This manuscript is a non-peer reviewed preprint uploaded to EarthArXiv as an openaccess contribution.

\title{
External control and automatic calibration of the HEC-RAS NSM-I water quality model
}

$$
\text { Diego Reginatto de Lima }
$$

Instituto de Pesquisas Hidráulicas, Universidade Federal do Rio Grande do Sul, Porto Alegre, Brasil.

\section{Fernando Mainardi Fan ${ }^{1}$}

Instituto de Pesquisas Hidráulicas, Universidade Federal do Rio Grande do Sul, Porto Alegre, Brasil.

Vinicius Alencar Siqueira

Instituto de Pesquisas Hidráulicas, Universidade Federal do Rio Grande do Sul, Porto Alegre, Brasil.

\footnotetext{
${ }^{1}$ Corresponding Author. Email: fernando.fan@ufrgs.br
} 
This manuscript is a non-peer reviewed preprint uploaded to EarthArXiv as an openaccess contribution.

\section{Abstract}

Calibration of models is a common procedure required to properly reproduce a system under analysis. In the present study, we developed a tool integrating the HEC-RAS NSM-I water quality model with the optimization algorithm SCE-UA in order to allow the automatic calibration. The tool's performance was assessed in two experiments involving a theoretical situation, when it was used to approximate a previously known set of parameters, and a real world application, when the tool was employed to calibrate a water quality model of the Gravataí River, Brazil. The results showed a good capacity to approximate the true parameters values in the theoretical experiment and a good consistency and agreement with reference values in the second experiment. Although future testing and improvements are possible, the proposed approach can be an useful alternative in water quality modeling using HEC-RAS.

Keywords: Model Calibration, Multiobjective-optimization, river water quality modeling, HECRAS 
This manuscript is a non-peer reviewed preprint uploaded to EarthArXiv as an openaccess contribution.

\section{Software Availability:}

Name of software: The software described in this paper is the NSM-Controller, a tool that couples both the SCE-UA and the HEC-RAS NSM-I Water Quality Model allowing the automatic calibration.

Hardware and Software Requirements: Any windows computer should be able to run the tool. HEC-RAS 5.06, HEC-DSS VUE 2.0.1 and Excel (or equivalent software capable of managing VBA) are required.

Availability: The NSM-Controller and its manual can be downloaded from: https://www.ufrgs.br/lsh/products/nsm-calibrator/ 
This manuscript is a non-peer reviewed preprint uploaded to EarthArXiv as an openaccess contribution.

\section{Introduction}

Water quality is a problem of special concern due to its economic, social and environmental implications, especially in rivers which are extensively used as water supply to human activities, but simultaneously, receive wastewater discharges and have a relevant ecological role. In this context, river water quality modeling can be an useful tool for diagnostic and compliance evaluation, optimal allocation of effluent discharges (Andrade et al., 2013), decision making regarding environmental restoration programs (Ning et al., 2001; Zhang et al., 2012) and evaluation of potential impacts related to the installation of projects and land use changes (Zhang and Wu 2013; Demissie et al. 2017).

Typically, water quality models have parameters that need to be known in order to properly reproduce the process occurring in the river under analysis. Due to the difficulty to directly determinate, the parameters definition is usually made through calibration. When manual, calibration is a trial and error process in which the analyst varies the values of the parameters and evaluates the response, usually being a time consuming and subjective process in some extent. On the other hand, the automatic calibration involves the application of optimization algorithms to determine the values for the parameters that guarantee the best adjustment between the simulated data and the observed control data (Duan et al., 1994; Yapo et al., 1998; Gupta et al., 1998; Goktas and Aksoy, 2005; Pelletier et al., 2006). Examples of automatic calibration in water quality modeling include Van Griensven and Bauwens (2003), which uses the SCE-UA to calibrate the model ESWAT and Pelletier et al. (2006), which integrates the Qual2K water quality model and the genetic algorithm PIKAIA.

The necessity of determining the best values for a set of parameters that minimize the error of a model or provide the best result for an optimization problem it's a common issue for many fields of knowledge which motivated the development of many algorithms. Examples of calibration algorithms include the Simplex (Nelder and Mead, 1965), the Genetic Algorithms (John Holland 1975), Particle Swarm Optimization (Kennedy and Eberhart, 1995), Ant Colony Optimization (Dorigo, 1992), Differential Evolution (Storn and Price in 1997), Artificial Bee Colony (Karaboga, 2005), Shuffled Complex Evolution (SCE-UA, from Duan et al. 1992), Multiple-Objective Complex Evolution (MOCOM-UA, from Yapo et al., 1998) and Multi-objective Shuffled Complex Evolution Metropolis (MOSCEM-UA, from Vrugt et al., 2003).

Among those, the SCE-UA, originally developed for calibration of hydrologic models, has been extensively applied and adapted in hydrology and in others fields like climatology (Liu et al., 2005), remote sensing ( $\mathrm{Xu}$ et al., 2011), groundwater management ( $\mathrm{Wu}$ and Zhu, 2006), reservoir operation (Lin et al., 2008, Tucci et al., 2008), erosion and hidrossedimentology (Santos et al., 1999), real time updating for stream flow forecasting (Siqueira et al., 2016) and machine learning ( $\mathrm{Li}$ et al., 2007). The algorithm combines deterministic and probabilistic approaches and concepts like competitive evolution and complex shuffling to find the global optimum of a mono-objective optimization problem. 
Considering the benefits of the automatic calibration and because of the considerable efforts and time needed for manually adjusting the parameters of HEC-RAS NSM-I model, the objective of this work is to develop and assess an automated calibration tool that allows the coupling between HEC-RAS NSM-I and the SCE-UA optimization algorithm. Next sections are organized as follows: (i) brief description about the HEC-RAS NSM model, (ii) concepts about the optimization procedure, SCE-UA algorithm (iii) the steps for integrating HEC-RAS NSM to SCE-UA and (iv) description of two experiments carried out in a hypothetical river with standardized dimensions, and in the Gravataí River located in the Porto Alegre metropolitan region, Brazil.

\section{Metholds}

\subsection{HEC-RAS model}

HEC-RAS is a software developed by the USACE (U.S. Army Corps of Engineers), capable of simulating 1D and 2D river hydraulics, sediment transport dynamics and water quality modeling. The water quality model utilizes the QUICKEST-ULTIMATE (Leonard et al., 1991) numerical scheme in order to solve the advection-diffusion equation in an one-dimensional finite volume scheme. As a prerequisite for the execution of a simulation, the HEC-RAS water quality module requires hydraulic data (e.g. flow rate, velocity...) obtained by running a hydraulic simulation in steady or unsteady state. The HEC-RAS version 5.06, used in the present paper, has 4 water quality simulations modes: temperature, total dissolved gas, NSM I, and arbitrary constituents. We utilized the NSM I mode which is capable of modeling the transport and fate of Carbonaceous BOD, Dissolved Oxygen, Algae, Phosphorus (organic and orthophosphate) and nitrogenous compounds (organic, $\mathrm{NO}_{2}, \mathrm{NO}_{3}$ and $\mathrm{NH}_{4}$ ).

\subsection{Automatic Calibration of Models}

\subsubsection{General description}

The automatic calibration consists of an optimization process that seeks to determine the model coefficients that produce the best adjustment between the observed and simulated data. The evaluation of the adjustment is made through one or more objective functions. Mathematically, the optimization process can be expressed by:

$$
\begin{aligned}
& \text { Min or Max }\left\{\mathrm{f}_{1}(\overrightarrow{\mathrm{x}}), \mathrm{f}_{2}(\overrightarrow{\mathrm{x}}), \ldots \mathrm{f}_{\mathrm{n}}(\overrightarrow{\mathrm{x}})\right\} \quad \text { eq. } 1 \\
& \text { Subject to } \vec{x} \in S
\end{aligned}
$$

Where: $f_{1}, f_{2} \ldots f_{n}$ are the "n" objective functions to be optimized; $\vec{x}$ is the vector composed by the " $\mathrm{j}$ " parameters of the model to be calibrated: $\vec{x}=\left(x_{1}, x_{2} \ldots x_{j}\right)$; $\mathrm{S}$ is the feasible space, i.e., 
This manuscript is a non-peer reviewed preprint uploaded to EarthArXiv as an openaccess contribution.

the space between the lower values $\left(x_{j}^{i}\right)$ and higher values $\left(x_{j}^{s}\right)$ that the components of the vector $\vec{x}$ can assume, such that $x_{1}^{i}<x_{1}<x_{1}^{S} \ldots x_{\mathrm{j}}^{i}<x_{j}<x_{\mathrm{j}}^{S}$;

In water quality modeling, often is desirable to employ more than one objective function in order to achieve a better adjustment of each pollutant, substance or property (e.g. temperature) being modeled (Yapo et al., 1998; Pelletier et al., 2006). In this context, the optimization applied to water quality model calibration becomes a multi-objective problem and, therefore, is characterized by the inexistence of a unique solution capable of optimizing, simultaneously, all the conflicting objectives that are usually given by a set of objectives function, each one representing the error of the simulation every modeled substance or constituent. Thus, the result of a multi-objective calibration is a group of equivalent solutions, denominated NonDominated Solutions or Pareto Optimal and which together form the so called Pareto Front.

In some cases is acceptable or even desirable to have more than solution, like in a hydrologic model where a set of parameters could better represent the dry season and another set, the wet season (Gupta et al., 1998; Yapo et al., 1998; Tucci et al., 2009). However, it is often necessary to obtain a single response that represents a best compromise solution. They are many methods to select the best compromise solution between the non-dominated solutions, including aggregation schemes, goal programming, global criterion and the constraint method. In the present study we use an aggregation scheme, also known as linear combination of weights or weighted sum method, which is extensively applied due its simple implementation and because it transforms a multi-objective problem into a mono-objective one by combining two or more objective functions by employing weighting factors (Efstratiadis and Koutsoyiannis, 2010; Chiandussi et al., 2012; Odu and Owaba, 2013). Equation 2 presents the aggregation scheme utilized. In the aggregation scheme, each factor represents the relative importance of each goal. Furthermore, by varying the weighting factors it is possible to approximate the Pareto Front. However, it is valid to point the limitations of this approach, including a high computational effort and difficulties in non-convex regions (Chiandussi et al., 2012; Odu and Owaba, 2013).

$$
\text { F.O. }=\sum_{i=1}^{n} w_{i} f_{i} \quad \text { eq. } 2
$$

Where $f_{i}$ is the objective function for the constituent $i$ and $w_{i}$ the corresponding weighting factor.

\subsubsection{SCE-UA algorithm}

The SCE-UA is a mono-objective global optimization algorithm developed by Duan et al. (1992) specifically to deal with problems that typically arise in model calibrations, including many regions of attraction and local optima, rough and non-convex response surface and poor and varying sensitivity in region of the optimum, with non-linear parameter interactions (Duan et al., 1994). The algorithm seeks to determine the best set of value to "j" parameters of a model and 
is composed by the following steps: (i) Initialization, with the generation of "s" random points in the feasible parameters space; (ii) point ranking according to the value of the objective function, (iii) partition of the points in "p" complexes, each one containing " $m$ " points, (iv) independent evolution of the complexes according with the Competitive Complexes Evolution (CCE) algorithm (see below), (v) complex shuffling (vi) convergence check and reduction of complexes and return to step ii. The complex reduction, introduced by Duan et al. (1993), seeks to accelerate the SCE by progressively decreasing the number of complexes until a minimum number defined by the user $\left(p_{\min }\right)$ due to the continuous reduction of the search space as the algorithm progresses.

The CCE algorithm employs the concepts of reflection and contraction from the SIMPLEX method of Nelder and Mead (1965) to generate replacements to the worst points of a subcomplex, which is formed with " $q$ " points selected from each complex using a trapezoidal probability distribution. Additionally, in case of failure of the reflection and contraction steps in generating a better point inside the feasible space, the CCE employs a mutation step, when a random point is created. The CCE algorithm runs " $\beta$ " times for each complex, after which the complexes are shuffled in order to share the information obtained by the independent exploration of the feasible space by each one. Regarding the configuration of the SCE-UA algorithm, the authors recommended the use of $m=\beta=2 n+1, q=n+1$. In relation to $p$, Duan et al. (1994) demonstrate that for a problem with 6 parameters being calibrated, $p=2$ was sufficient to achieve the global optimum, while in situations of bigger complexity, a bigger value for $p$ was required.

\subsection{Integration between HEC-RAS and SCE-UA algorithm}

In order to reduce the time consumption and the supervision needed to manipulate the input files, we developed the NSM-Controller, a tool in VBA capable of fully automating the calibration process. The NSM-Controller couples both the SCE-UA and the HEC-RAS, allowing:

I. Generation of the input files for the water quality simulation with the candidate solutions data;

II. Execution of the HEC-RAS;

III. Results reading and;

IV. Application of the SCE-UA in order to generate a new candidate solution for the next iteration.

The automation of the HEC-RAS has already been explored by other studies such as in Leon and Goodell (2016), which present a series of scripts to control HEC-RAS via Matlab, and by Siqueira et al. (2016), which concomitantly optimized the manning values and produced lateral inflows using a synthetic hydrographs through VB.NET code programming. However, unlike previous works, the approach presented in our study focus on the calibration of the water quality model. 
To run a water quality simulation in HEC-RAS, a set of files are required, including a geometry file $\left({ }^{*} . \mathrm{gxx}\right)$ containing data from cross sections, river system schematics and hydraulic structures; a file with the flow data (".fxx or * ${ }^{*}$ uxx); a file with the water quality data ( ${ }^{*}$.wxx); and a plan file ( $\left.{ }^{*} . \mathrm{pxx}\right)$. The developed script focuses only on modifying the water quality data file ( $\left.{ }^{*} . w x x\right)$, while the remaining files are kept unaltered. The alterations comprise the update of the constants being calibrated according to the values provided by the SCE-UA. Once ready the water quality data file, the simulation is carried out using the HEC-RAS Controller module, which interfaces with the HEC-RAS allowing the external control. For reading the results, we utilized the HEC-DSS VUE, a tool developed by the USACE, capable of accessing and manipulating the DSS files, a type of data archive designed to store water resource information, commonly used by the USACE software including HEC-RAS and HEC-HMS. Figure 1 ilustrates the coupling pocess, emphasizing the procedures related to the integration with HEC-RAS: Water Quality file Update, HEC-RAS Execution and Results Reading. Regarding the SCE-UA algorithm, after the random inicialization, the candidate solutions are tested in HEC-RAS and based on the results, the solutions are ranked and the complexes are formed and the evolution in the CCE starts.

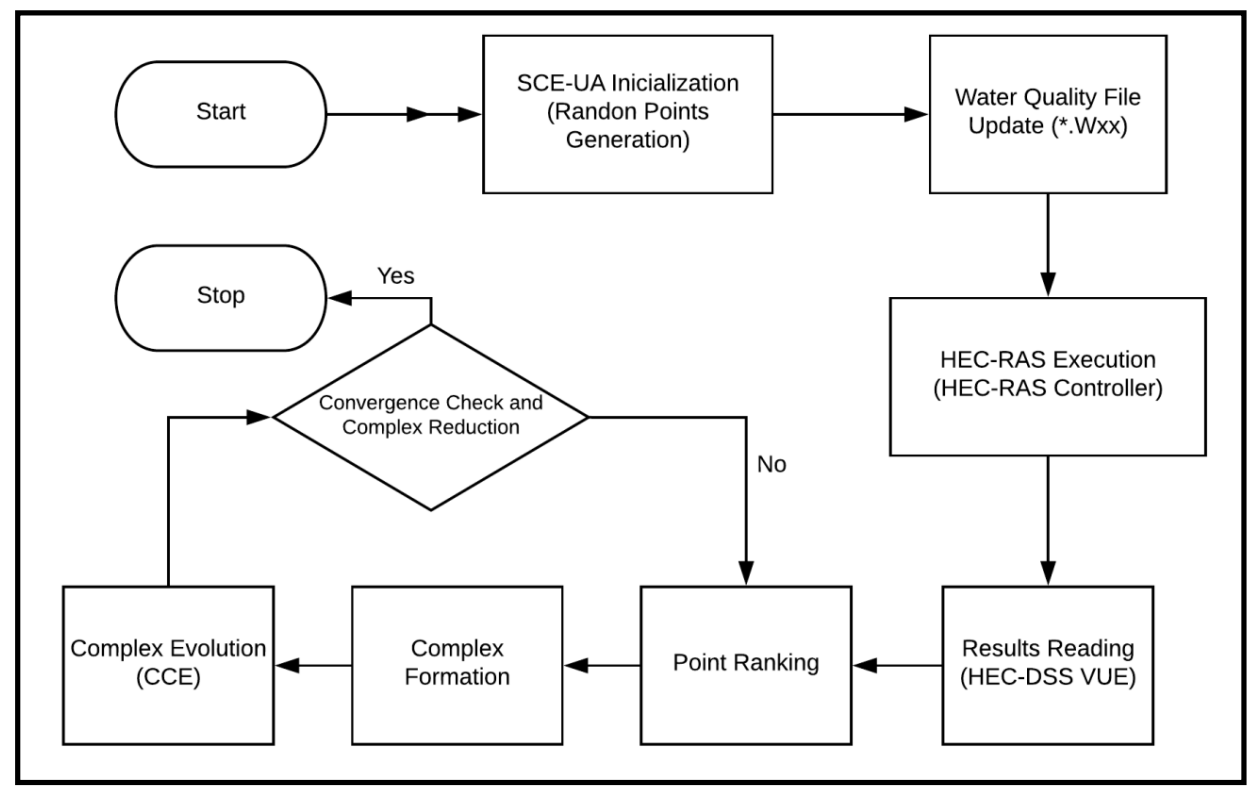

Figure 1: SCE-UA coupled with HEC-RAS water quality model.

In figure 2, is presented the flowchart of the CCE-UA algorithm, where $\operatorname{Pr}, \mathrm{Pc}$ and $\mathrm{Pm}$ are, respectively, the points generated by the reflection, contration and mutation operators in order to generate a substitute for the worst subcomplex point (Pw). The interface with HEC-RAS follows the same steps as in SCE-UA (here unified in HEC-RAS interaction for simplicity purposes). After each evolution step (ib) the complex is updated and the process is restarted until the limit $\beta$ is achieved. Then the CCE returns its results for the SCE-UA, wich checks for convergence. If necessary, the process continues with new complexes being formed and sent to evolve in CCE until convergence is achieved. 


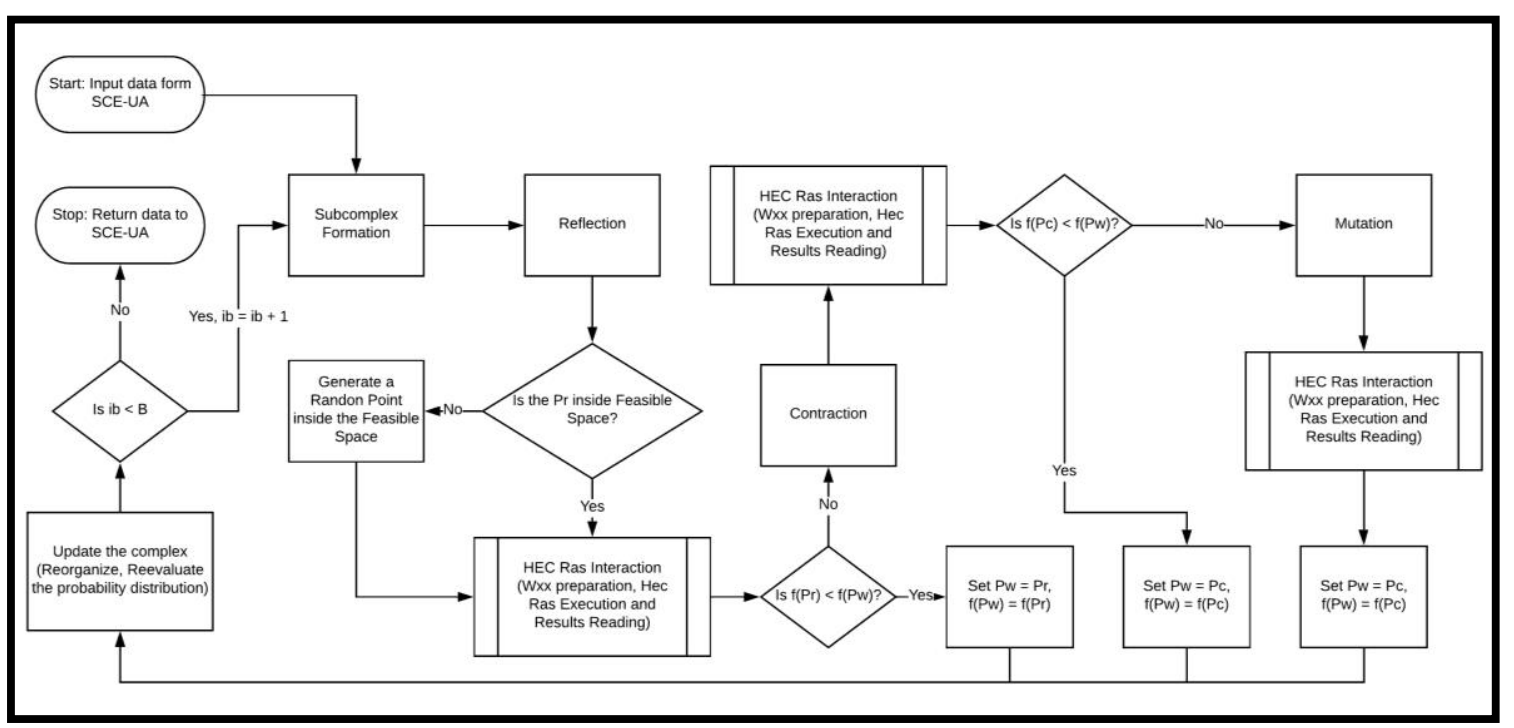

Figure 2: Interaction between CCE-UA, HEC-RAS and SCE-UA

In the NSM-controller we implemented two objective functions, but others can be easily implemented by the user, if required. The Root Mean Square Error (RMSE) is one of the most popular performance metrics and has the characteristic of giving a greater emphasis to the larger values. In contrast, the Transformed RMSE (TRMSE) is an adaptation of the RMSE that seeks to emphasize the smaller values (Wagener et al., 2009). For the experiments, we utilized only the TRMSE, which is presented below:

$$
\text { TRMSE }=\sqrt{\frac{1}{m} \sum_{x=1}^{m}\left(Z S_{x}-Z O_{x}\right)^{2} ;} \quad Z S_{x}=\frac{\left(1+S_{x}\right)^{\gamma}-1}{\gamma} ; \quad Z O_{x}=\frac{\left(1+O_{x}\right)^{\gamma}-1}{\gamma} \quad \text { eq. } 3
$$

Where: $S$ are the simulated values, $O$ are the observed values, $x=1,2, \ldots \mathrm{m}$ are the several points with available data, ZO and ZS are the transformed concentrations and $y=0.3$. (Wagener et al., 2009).

\subsection{Experimental setup}

In order to evaluate the integration between the HEC-RAS and the SCE-UA and its efficacy, we prepared two experiments. The first one involves the application of the SCE-UA to calibrate the parameters from the HEC NSM I water quality model in a hypothetical river with trapezoidal shape $(B=200 \mathrm{~m}, b=100 \mathrm{~m}, \mathrm{i}=0.0005 \mathrm{~m} / \mathrm{m}, \mathrm{Q}=100 \mathrm{~m} / \mathrm{s}, \mathrm{n}=0.03, \mathrm{l}=50 \mathrm{~km})$. Figure 3 shows the first experiment model in HEC-RAS. 


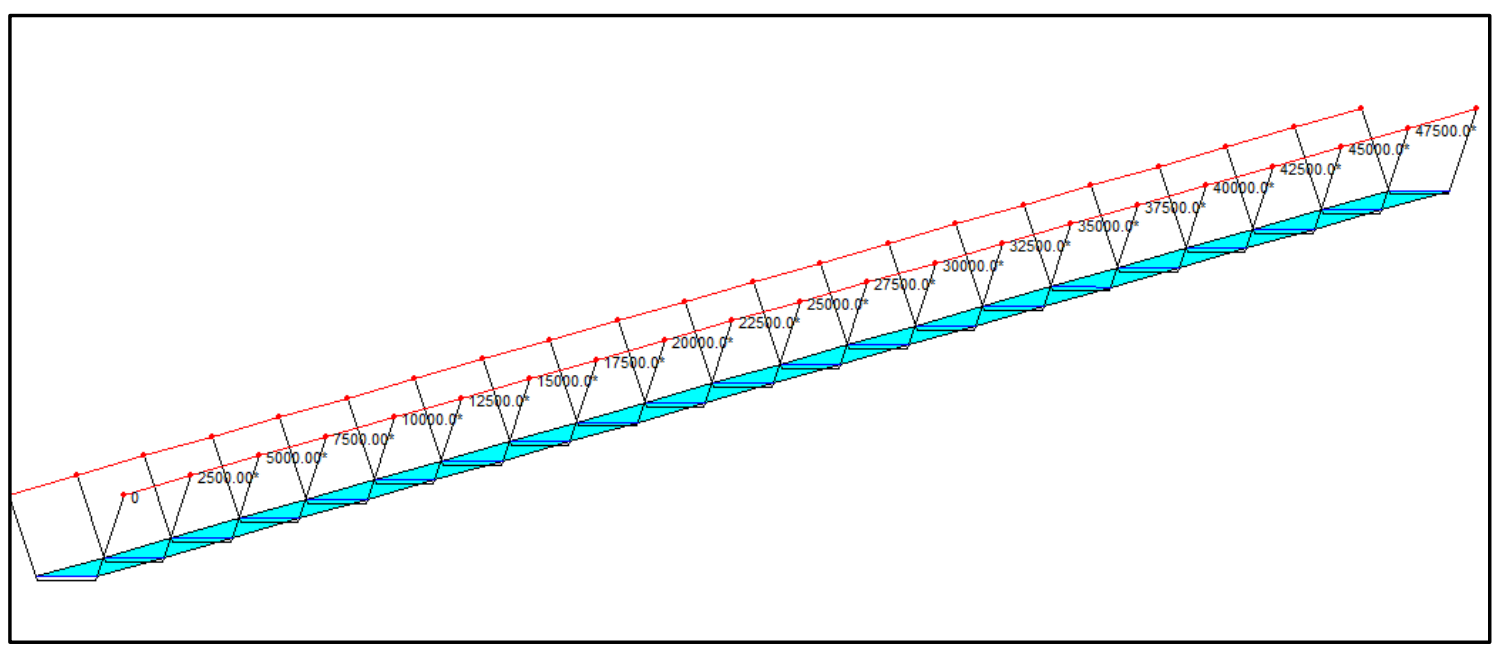

Figure 3: HEC-RAS Experiment I Model

Initially, the value for all the model parameters was arbitrated inside the range of recommended values and a water quality simulation was executed. Then, the results of this first simulation were used as control "observed" data in the subsequent calibration process. The objective of this experiment was to evaluate the ability of the NSM-Calibrator to approximate the original model parameters (hereafter named as true values) trough calibration.

We tested 5 scenarios with a number of parameters being calibrated varying between 2 and 12 , and executed 2 independent calibration tests in each scenario. In the scenarios, when a parameter was not being calibrated, its value was kept fixed in the same value used in the reference simulation. Table 1 shows the parameters calibrated in each scenario, the arbitrated value (true value) and the parameters range. The parameters range was defined based on HEC-RAS recommended values. For K4 we used data from Rong et al. (2016)

Table 1: Case Study I - Scenarios and Parameters

\begin{tabular}{|c|c|c|c|c|c|c|c|}
\hline \multirow{2}{*}{ Parameters } & \multirow{2}{*}{ True Value } & \multirow{2}{*}{ Range } & \multicolumn{5}{|c|}{ Scenarios } \\
\hline & & & $\mathbf{A}$ & B & $\mathbf{C}$ & D & 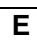 \\
\hline K1 = CBOD Decay Rate $\left(\right.$ day $\left.^{-1}\right)$ & 1.2 & $0.02-3.4$ & $\bar{X}$ & & $\mathrm{X}$ & & $\mathrm{X}$ \\
\hline K2 = Atmosferic Reareation $\left(\right.$ day $^{-1}$ ) & 15 & $0-100$ & $\mathrm{X}$ & & $\mathrm{X}$ & & $\mathrm{X}$ \\
\hline K3 = CBOD Settling Rate $\left(\right.$ day $\left.^{-1}\right)$ & 0.1 & $-0.36-0.36$ & & & $\mathrm{X}$ & & $\mathrm{X}$ \\
\hline K4 = Sediment Oxygen demand $\left(\mathrm{g} / \mathrm{m}^{2}\right.$. day $\left.^{-1}\right)$ & 1 & $0-1.82$ & & & $\mathrm{X}$ & & $\mathrm{X}$ \\
\hline$\beta 1=\mathrm{NH} 4$--> NO2 $\left(\right.$ day $\left.^{-1}\right)$ & 0.55 & $0.1-1$ & & $\mathrm{X}$ & & $\mathrm{X}$ & $\mathrm{X}$ \\
\hline$\beta 2=\mathrm{NO} 2-->\mathrm{NO} 3\left(\right.$ day $\left.^{-1}\right)$ & 1.8 & $0.2-2$ & & $\mathrm{X}$ & & $\mathrm{X}$ & $\mathrm{X}$ \\
\hline$\beta 3=$ OrgN -->NH4 $\left(\right.$ day $\left.^{-1}\right)$ & 0.1 & $0.02-0.4$ & & $\bar{X}$ & & $\bar{X}$ & $\mathrm{X}$ \\
\hline$\beta 4=$ OrgP $-->\operatorname{lnorg} P\left(\right.$ day $\left.^{-1}\right)$ & 0.5 & $0.01-0.7$ & & $\mathrm{X}$ & & $\mathrm{X}$ & $\mathrm{X}$ \\
\hline$\alpha 1=$ Biomas (Nitrogen Fraction) $(\mathrm{mgN} / \mathrm{mgA})$ & 0.08 & $0.07-0.09$ & & & & $\mathrm{X}$ & $\mathrm{X}$ \\
\hline$\alpha 2=$ Biomas (Phosphorus Fraction) $(\mu \mathrm{gP} / \mathrm{mgA})$ & 0.012 & $0.01-0.02$ & & & & $\mathrm{X}$ & $\mathrm{X}$ \\
\hline$\alpha 3=$ DO Production per unit algal growth (mgO/mgAp) & 1.7 & $1.4-1.8$ & & & & $\mathrm{X}$ & $\mathrm{X}$ \\
\hline $\mathrm{a} 4$ = DO Uptake per unit algal respired (mgO/mgAp) & 1.8 & $1.6-2.3$ & & & & $\mathrm{X}$ & $\mathrm{X}$ \\
\hline
\end{tabular}


Furthermore, one objective function was assigned to evaluate the adjustment of each modeled constituent (CBOD, DO, organic nitrogen, $\mathrm{NO}_{2}, \mathrm{NO}_{3}$ and $\mathrm{NH}_{4}$, algae, organic phosphorus and orthophosphate) totalizing 9 objective functions combined by the aggregation scheme (eq. 2) with equally weighted factors. Temperature was kept fixed and we used 10 equally spaced cross sections in the error calculation. As for the SCE-UA, we used the standard configuration $m=\beta=2 n+1, q=n+1$. Regarding the number of complexes, we used $p=2$ for scenario $A, p=$ 4 for scenarios $B$ and $C, p=5$ for scenario $D$ e $p=6$ for scenario $E$. Pmin was set as 2 for the scenarios $A, B$ and $C$ and 3 for the scenarios $D$ and $E$. The stopping criteria utilized were maximum number of complexes shuffle (25) and TRMSE error $\left(<1.10^{-3}\right)$. Besides the number of parameters being calibrated and the SCE configuration, all remaining characteristics of the experiment I were kept fixed in all the scenarios.

In the experiment II, we evaluated the NSM-Controller in the calibration of a water quality model of the Gravataí River, located in the Metropolitan Region of Porto Alegre, Rio Grande do Sul State, and one of the most polluted rivers in Brazil. Figure 4 shows the Rio Gravataí and its main tributaries in the study area and figure 5 the model in HEC-RAS.

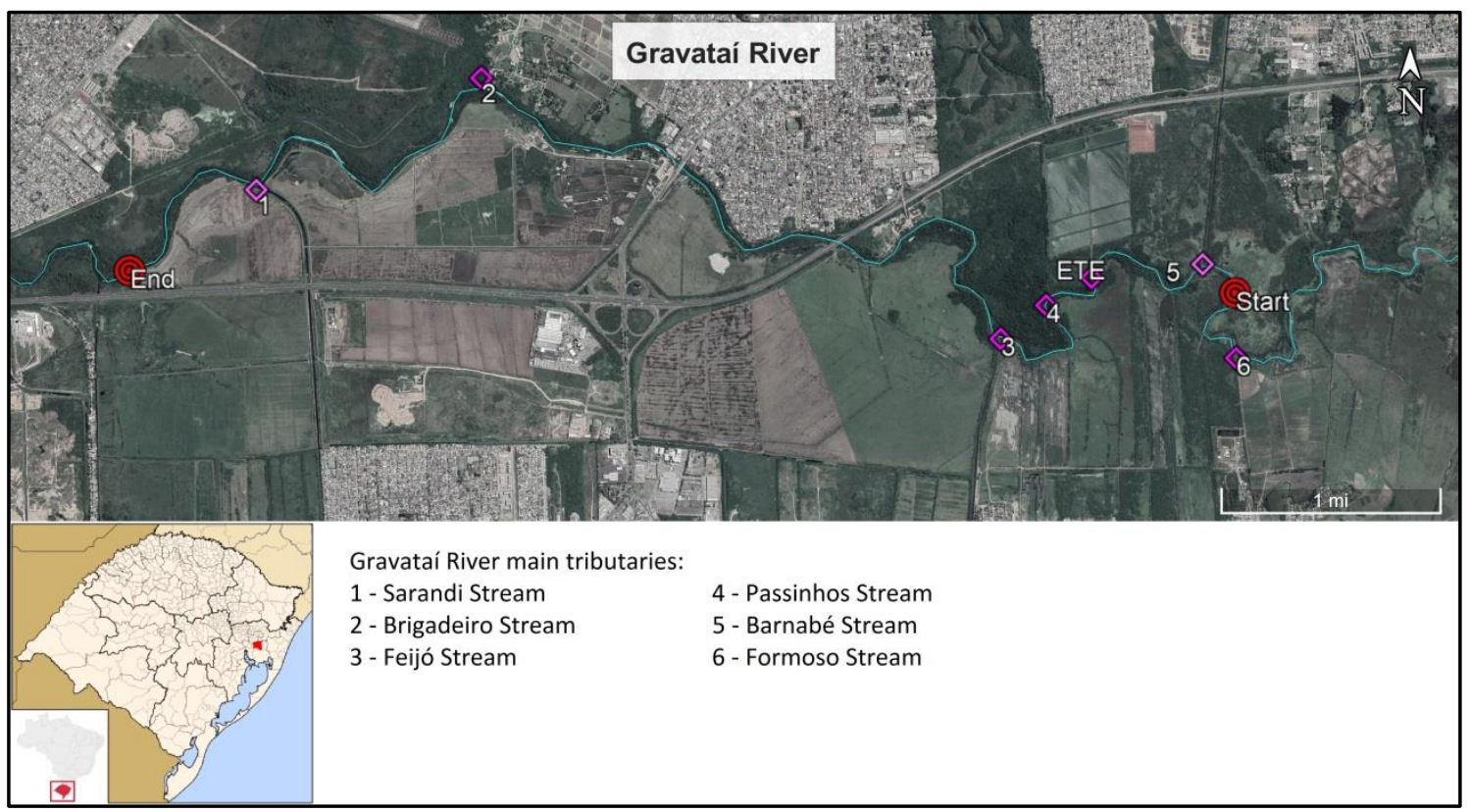

Figure 4: Experiment II - Rio Gravataí modeled reach in the Rio Grande do Sul State, Brazil. 


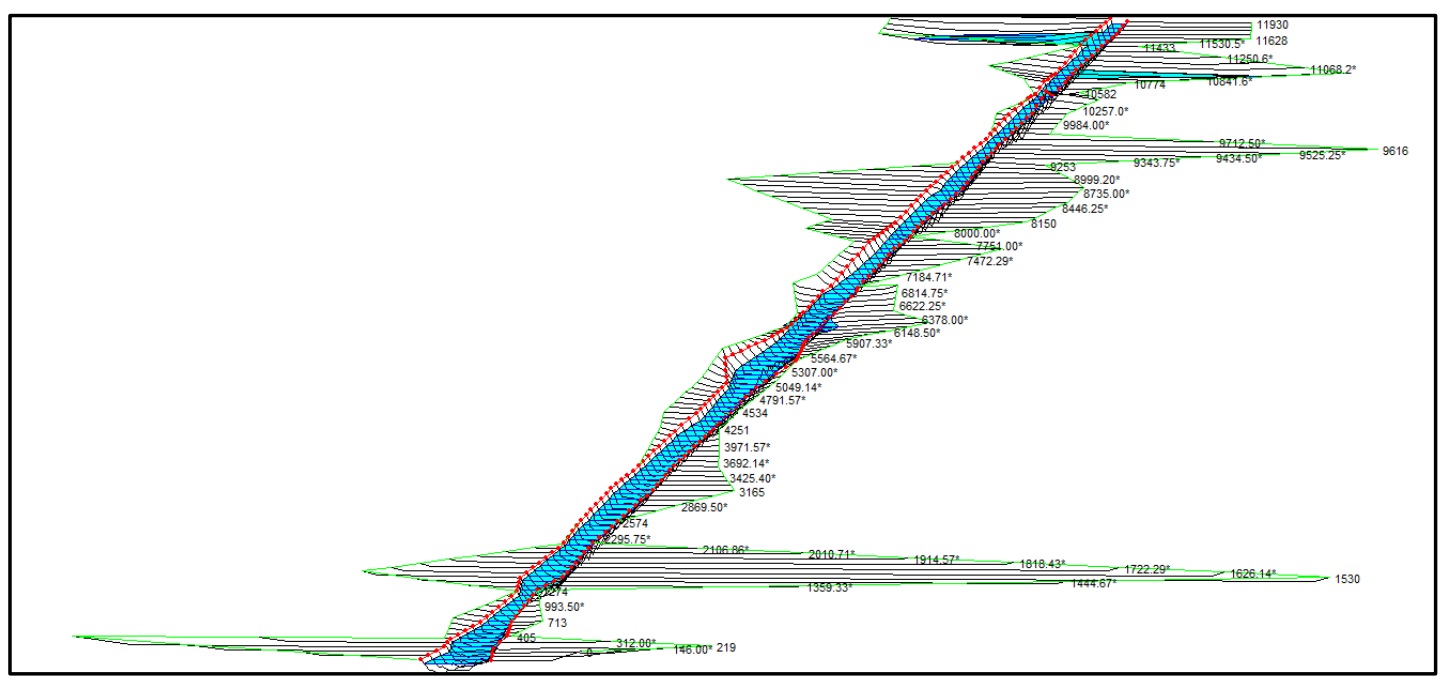

Figure 5: HEC-RAS Case Study II Model

In order to reduce the data requirements and considering characteristics of the study reach, including pollution associated with urban sewage and short detention period, which minimizes de importance of the nitrogenous demand when compared with the carbonaceous demand, we only modeled the dynamics of DO and CBOD. The Data from water quality (DO and CBOD) was collected during February of 2017 (Brazilian summer, with higher temperatures and lower discharge) in the mouth of the main tributaries, which drain the urban area and receive effluents discharges, and in a sewage treatment plant, which treats a portion of the domestic sewage generated in the region. Additionally, 4 others points were sampled in order to provide data for calibration. At same time, in order to provide data for the hydraulic model, we measured the water level in a monitoring station and the stream flow was determined utilizing discharge rating curves.

The hydraulic model of the river, required for the water quality simulation, was constructed using data from local assessments studies (Consórcio Gravataí, 2016a; Consórcio Gravataí, 2016b) and from Hidroweb portal (Brazilian hydrological database). In possession of all the water quality and hydraulic data, the calibration process was carried out in order to determine the values of the constants K1 (CBOD decay rate), K2 (reaeration), K3 (CBOD settling rate), and K4 (sediment oxygen demand). Two objective functions were employed in order to evaluate the adjustment of DO and CBOD. As for the aggregation scheme, we used weighting factors varying between 0 and 1 in order to obtain a set of solution representing the best compromise and solutions prioritizing the adjustment of $\mathrm{DO}$ and $\mathrm{CBOD}$.

In the experiment II, the objective function chosen to evaluate the adjustment of each constituent was the TRMSE, the water temperature was set constant and the recommended values for the SCE parameters were adopted: $m=\beta=2 n+1, \alpha=1$, q. $P$ was set to 4 , and Pmin to 2 . The convergence criteria utilized were maximum number of complexes shuffle (25) and TRMSE error $\left(<1.10^{-3}\right)$. 
This manuscript is a non-peer reviewed preprint uploaded to EarthArXiv as an openaccess contribution.

\section{Results and Discussion}

The tool, developed in VBA and with an interface in an Excel worksheet allows the user to define which parameters will be calibrated, the objective function and weighting factors to be used, and the observed data employed in the error calculation. Following, we present the results obtained in each of the two experiments designed to test the developed tool.

\subsection{Experiment I}

In the experiment I, the results demonstrated a good capacity of the NSM-Controller to approximate the true values used in the reference simulation and reduce the error evaluated by the objective functions, especially in the scenarios $A$ and $B$, in which the convergence criteria of 0.001 was achieved before 25 shuffles defined as alternative stopping criteria. Table 2 presents the initial and final error evaluated by the objective function TRMSE for the best solution and the number of HEC-RAS simulations executed.

Table 2: Experiment I - Calibration Results

\begin{tabular}{|l|l|l|l|l|l|l|l|l|l|l|}
\hline \multirow{2}{*}{ Result } & \multicolumn{2}{|l|}{ Scenario A } & \multicolumn{2}{l|}{ Scenario B } & \multicolumn{2}{l|}{ Scenario C } & \multicolumn{2}{l|}{ Scenario D } & \multicolumn{2}{l|}{ Scenario E } \\
\cline { 2 - 11 } & Test 1 & Test 2 & Test 1 & Test 2 & Test 1 & Test 2 & Test 1 & Test 2 & Test 1 & Test 2 \\
\hline $\begin{array}{l}\text { Initial Error (best } \\
\text { solution - random } \\
\text { initialization) }\end{array}$ & 0.9980 & 0.6610 & 0.4815 & 0.4831 & 1.2397 & 1.5021 & 0.2641 & 0.2324 & 1.3634 & 1.3934 \\
\hline $\begin{array}{l}\text { Final Error (best } \\
\text { solution) }\end{array}$ & 0.0005 & 0.0008 & 0.0008 & 0.0007 & 0.0131 & 0.0093 & 0.0202 & 0.0233 & 0.1609 & 0.2146 \\
\hline $\begin{array}{l}\text { Number of HEC- } \\
\text { RAS Simulations }\end{array}$ & 279 & 309 & 639 & 793 & 961 & 939 & 2573 & 2611 & 4094 & 4004 \\
\hline
\end{tabular}

Regarding the error evaluated by the objective function, in all scenarios it is possible to observe a reduction when comparing the initial error from the best solution generated in the random initialization of the SCE-UA with best solution after the conclusion of the algorithm. In figures 6 to 10 are presented the error evolution along the calibration process for the best solution. In figure 11, is also presented the evolution of the mean error (all candidate solutions considered) for scenario $D$.

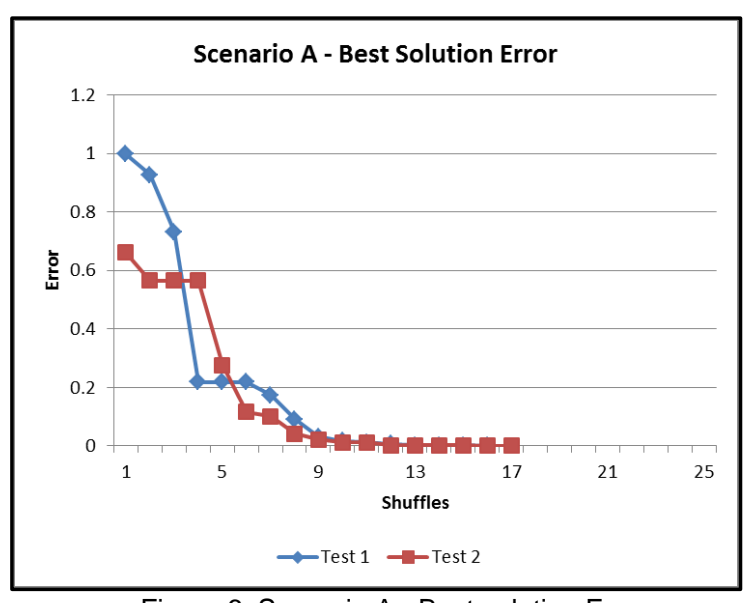

Figure 6: Scenario A - Best solution Error.

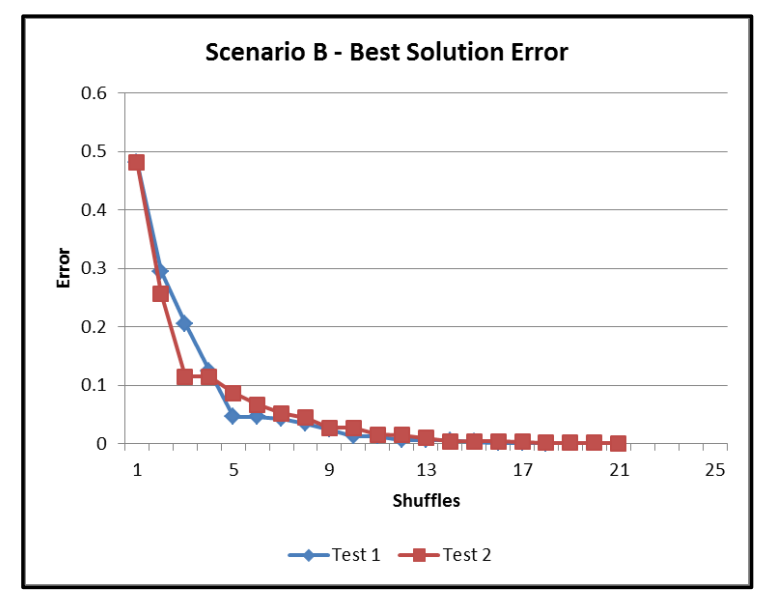

Figure 7: Scenario B - Best solution Error. 
This manuscript is a non-peer reviewed preprint uploaded to EarthArXiv as an openaccess contribution.

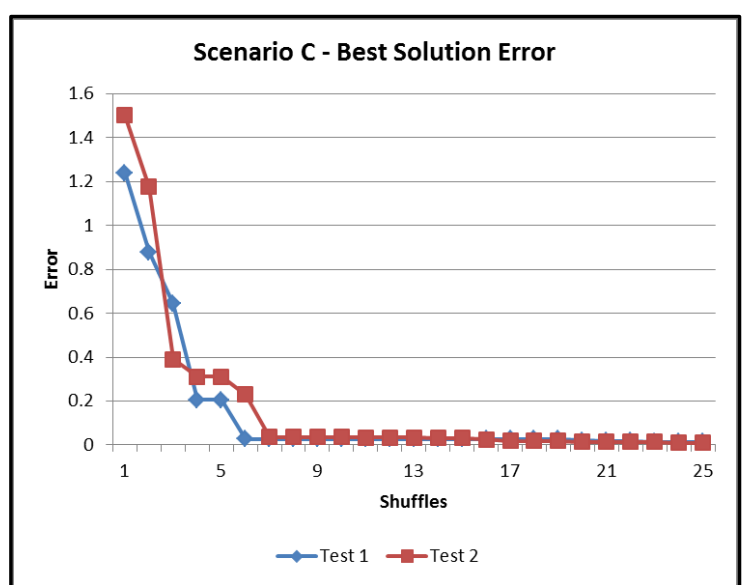

Figure 8: Scenario C - Best solution Error.

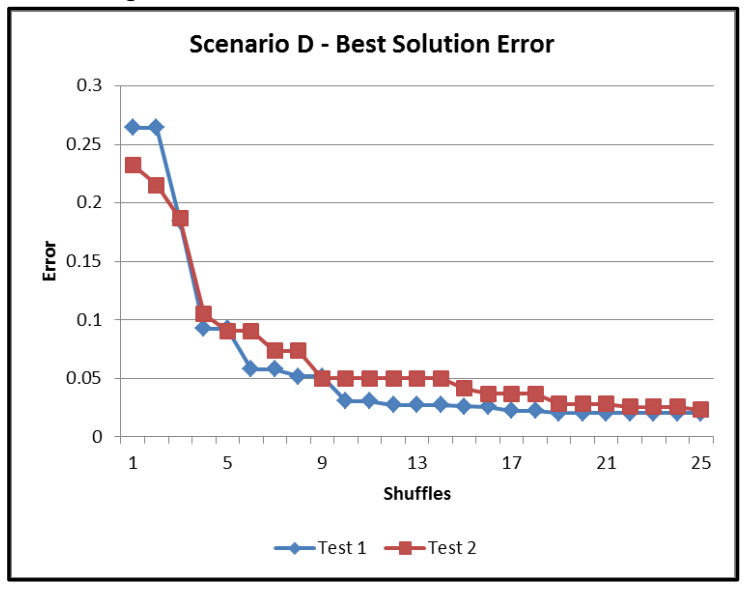

Figure 9: Scenario D - Best solution Error.

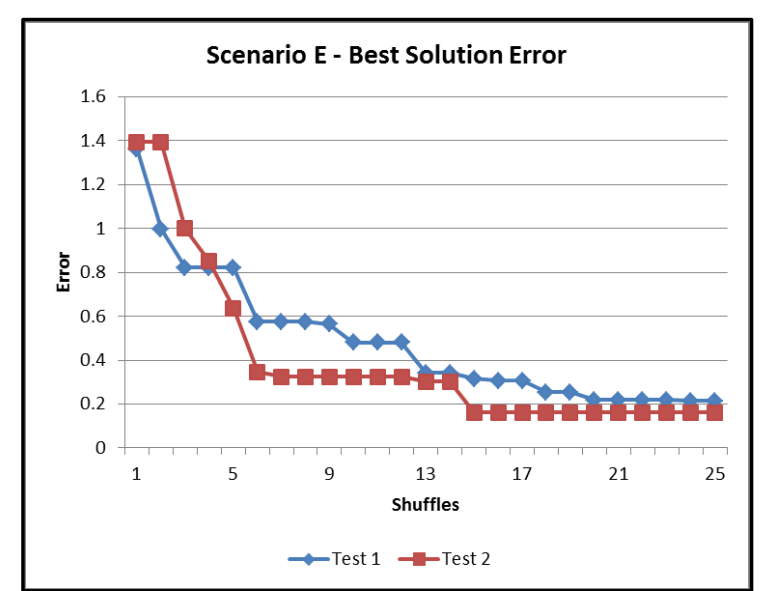

Figure 10: Scenario E - Best solution Error.

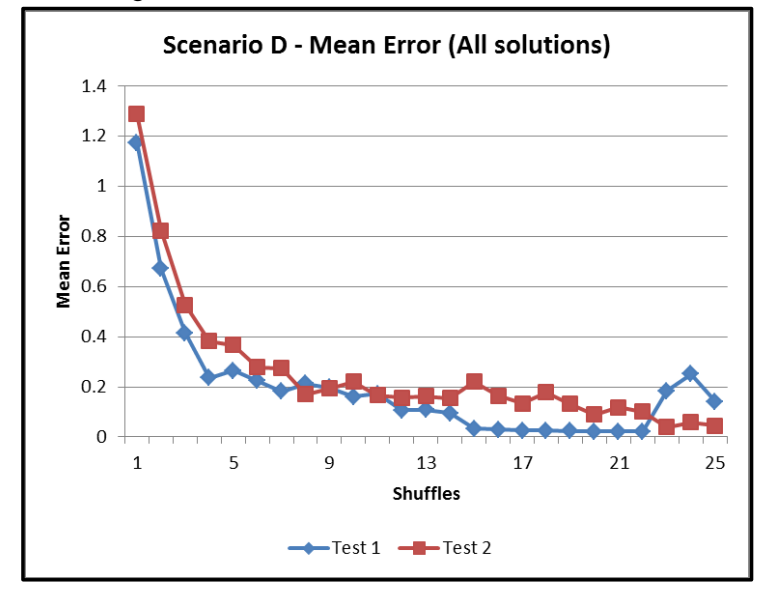

Figure 11: Scenario D - Mean Error.

All scenarios showed a rapid decrease in the error in the beginning of the calibration procedure, with stagnation in the final, meaning a higher computational effort to a smaller improvement in solution quality. In the higher dimensionality scenarios, it is also possible to observe the formation of plateaus when there is temporarily no improvement of the best solution, probably due to the stagnation in local minima. In order to escape those local minima, the algorithm employs nondeterministic mechanisms (i.e. mutation step). The effect of these mechanisms is demonstrated by fluctuations in figure 11, which shows the mean error of all solutions at end of each shuffle.

As for the NSM-Controller ability to approximate the real parameters value, the results were satisfactory. The parameters values obtained for the best solution in each calibration procedure executed in the experiment I is presented in table 3.

Table 3: Experiment I - Calibration Results

\begin{tabular}{|l|l|l|l|l|l|l|l|l|l|l|l|l|}
\hline \multirow{2}{*}{ Par. } & \multicolumn{2}{|l|}{ Scenario A } & \multicolumn{2}{l|}{ Scenario B } & \multicolumn{2}{l|}{ Scenario C } & \multicolumn{2}{l|}{ Scenario D } & \multicolumn{2}{l|}{ Scenario E } & \multirow{2}{*}{ True Value } \\
\cline { 2 - 10 } & Test 1 & Test 2 & Test 1 & Test 2 & Test 1 & Test 2 & Test 1 & Test 2 & Test 1 & Test 2 & \\
\hline K1 & 1.199 & 1.199 & - & - & 1.206 & 1.221 & - & - & 1.358 & 1.321 & 1.2 \\
\hline K2 & 15.002 & 14.998 & - & - & 15.048 & 15.256 & - & - & 17.239 & 16.500 & 15 \\
\hline K3 & - & - & - & - & 0.094 & 0.075 & - & - & -0.069 & -0.061 & 0.1 \\
\hline K4 & - & - & - & - & 1.203 & 0.978 & - & - & 0.740 & 1.441 & 1 \\
\hline$\beta 1$ & - & - & 0.649 & 0.650 & - & - & 0.634 & 0.635 & 0.654 & 0.597 & 0.65 \\
\hline
\end{tabular}



contribution.

\begin{tabular}{|l|l|l|l|l|l|l|l|l|l|l|l|}
\hline B2 & - & - & 1.799 & 1.799 & - & - & 1.755 & 1.759 & 1.716 & 1.586 & 1.8 \\
\hline B3 & - & - & 0.100 & 0.100 & - & - & 0.094 & 0.094 & 0.082 & 0.101 & 0.1 \\
\hline B4 & - & - & 0.498 & 0.499 & - & - & 0.505 & 0.500 & 0.494 & 0.400 & 0.5 \\
\hline$\alpha 1$ & - & - & - & - & - & - & 0.081 & 0.080 & 0.082 & 0.079 & 0.08 \\
\hline$\alpha 2$ & - & - & - & - & - & - & 0.013 & 0.014 & 0.014 & 0.013 & 0.012 \\
\hline$\alpha 3$ & - & - & - & - & - & - & 1.610 & 1.599 & 1.565 & 1.594 & 1.7 \\
\hline$\alpha 4$ & - & - & - & - & - & - & 1.888 & 1.876 & 1.939 & 2.120 & 1.8 \\
\hline
\end{tabular}

When evaluating the results, it becomes evident that, in the scenarios of lower dimensionality, the SCE-UA was able to achieve an almost perfect approximation for the HEC-RAS parameters used in the reference simulation. However, on higher dimensionality scenarios, the approximation lost quality, especially in the scenario E, when 12 parameters were calibrated. This suggests the necessity of a higher number of shuffles and complexes being employed in the calibration process, but, due to computational resources limitations calibrations, those were not carried out. Furthermore, considering that the HEC-RAS NSM I has 62 parameters, although many of them are temperature correction coefficients or associated with the optional benthic algae simulation, for real world applications the user will probably have to define priority parameters to be calibrated. The selection of parameters could be supported by sensitivity analysis or by characteristics from the study area.

\subsection{Experiment II}

Experiment II involves the calibration of a water quality model for the Gravataí River, in southern Brazil. We worked with 5 sets of weighting factors and the results are presented in the table 4. Due to being a real world application, there are no known values for the parameters.

Table 4: Experiment II - Calibration Results

\begin{tabular}{|c|c|c|c|c|c|c|c|c|c|}
\hline \multicolumn{6}{|c|}{ Weighting Factors } & \multicolumn{5}{|c|}{ Test 1 } & \multicolumn{4}{c|}{ Test 2} \\
\hline DO & BOD & K1 & K2 & K3 & K4 & K1 & K2 & K3 & K4 \\
\hline 1 & 0 & 2.276 & 1.817 & 0.137 & 1.716 & 2.334 & 1.754 & 0.146 & 0.597 \\
\hline 0.75 & 0.25 & 0.021 & 0.231 & 0.001 & 1.766 & 0.020 & 0.239 & $101.10^{-6}$ & 1.800 \\
\hline 0.5 & 0.5 & 0.020 & 0.234 & $203.10^{-6}$ & 1.816 & 0.020 & 0.239 & $139.10^{-6}$ & 1.802 \\
\hline 0.25 & 0.75 & 0.022 & 0.133 & 0.022 & 0.575 & 0.020 & 0.227 & $472.10^{-6}$ & 1.675 \\
\hline 0 & 1 & 0.020 & 40.738 & $15.10^{-6}$ & 1.365 & 0.020 & 31.653 & $17.10^{-6}$ & 0.460 \\
\hline
\end{tabular}

It is noticeable that when aggregating $D O$ and $B O D$ in the objective function with the sets of weighting factors of [WDO $=0.75, \mathrm{WBOD}=0.25]$ and $[\mathrm{WOD}=0.5$ e WDBO $=0.5]$, all the solutions converge to approximately the same values. These sets of parameters balance the importance of each constituent, providing solutions that can satisfy both. The consistency of the results strongly suggests that these are the most adequate parameters values. Furthermore, considering that the Gravataí is a polluted lowland river with low water velocities, those values are inside the expected range for river of the same characteristics ( see table 5 for reference values), although it's possible 
This manuscript is a non-peer reviewed preprint uploaded to EarthArXiv as an open-access contribution.

that non mapped discharges and process (e.g. nitrification) may have lowered the results for K2. Anyway, the main objective of the tests was to evaluate the developed tool.

Table 5: K1 and K2 Literature values

\begin{tabular}{|l|c|l|c|}
\hline Water Body & Parameter & $\begin{array}{c}\text { Range day - } \\
1\end{array}$ & Source \\
\hline Laboratory Study - sewage mixed with river water & K1 & $0.107-0.875$ & $\begin{array}{c}\text { Nuruzzaman et al. } \\
(2017)\end{array}$ \\
\hline Klamath River, EUA & K1 & $0.15-0.22$ & Sullivan et al. (2010) \\
\hline Wujin River, China & K1 & 0.23 & Zhang et al. (2015) \\
\hline Ribeirão Vermelho (small tropical urban stream, Brazil) & K1 & $0.07-0.15$ & Menezes et al. 2015 \\
\hline Untreated wastewater & K1 & $0.35-0.7$ & Chin (2006) \\
\hline Treated wastewater & K1 & $0.10-0.35$ & Chin (2006) \\
\hline Polluted river & K1 & $0.10-0.25$ & Chin (2006) \\
\hline Unpolluted river & K1 & $<0.05$ & Chin (2006) \\
\hline Wujin River, China & K1 & 0.23 & Zhang et al. (2015) \\
\hline Ribeirão Vermelho (small tropical urban stream, Brazil) & K2 & $2,5-14,58$ & Menezes et al. 2015 \\
\hline Small ponds and backwaters & K2 & $0.10-0.23$ & Chin (2006) \\
\hline Sluggish streams and large lakes & K2 & $0.23-0.35$ & Chin (2006) \\
\hline Large streams of low velocity & K2 & $0.35-0.46$ & Chin (2006) \\
\hline Large streams of normal velocity & K2 & $0.46-0.69$ & Chin (2006) \\
\hline Swift streams & K2 & $0.69-1.15$ & Chin (2006) \\
\hline Rapids and waterfalls & K2 & $>1.15$ & Chin (2006) \\
\hline $\begin{array}{l}\text { Various Large Rivers (discharges between 26.9 m³ sand 489 } \\
m^{3} / s\end{array}$ & K2 & $0.227-5.558$ & Churchill et al. (1964) \\
\hline Onondaga Lake & K2 & $0.02-0.38$ & Gelda et al. (1996) \\
\hline Tarawera (fast-flowing, turbulent) River & 2 & $7.19-8.62$ & Wilcock (1998) \\
\hline
\end{tabular}

However, when searched for solutions in the extremes of the Pareto Front [WOD $=1$,

$\mathrm{WDBO}=0]$ and $[\mathrm{WOD}=0, \mathrm{WDBO}=1]$ the results obtained by calibration were significantly different. In these situations, only the error of one constituent is considered and, therefore, the calibration is mono-objective. The results showed no consistency, and the values for the parameters were far from the expected values. This is most likely related to the structure of the equations that describe the interaction between DO and BOD, and reinforce the importance of a multi-objective approach when calibrating water quality models involving those constituents.

Regarding the error reduction, the SCE-UA provided a reduction but the results from experiment II were not as expressive as in experiment I. Although the error by itself is not directly comparable since the two experiments involve a different number of cross sections and objective functions employed in the error calculation, the reduction of the error is a reasonable metric of the improvement provided by calibration. Figure 12 and 13 show the error evolution along the shuffles for the best compromise solution and the mean error of all solutions. 


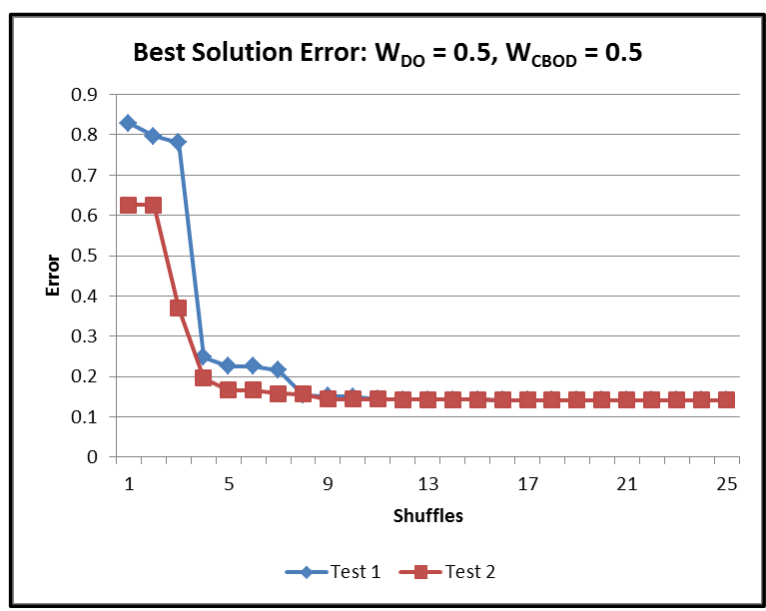

Figure 12: Experiment II - Best Compromise solution Error.

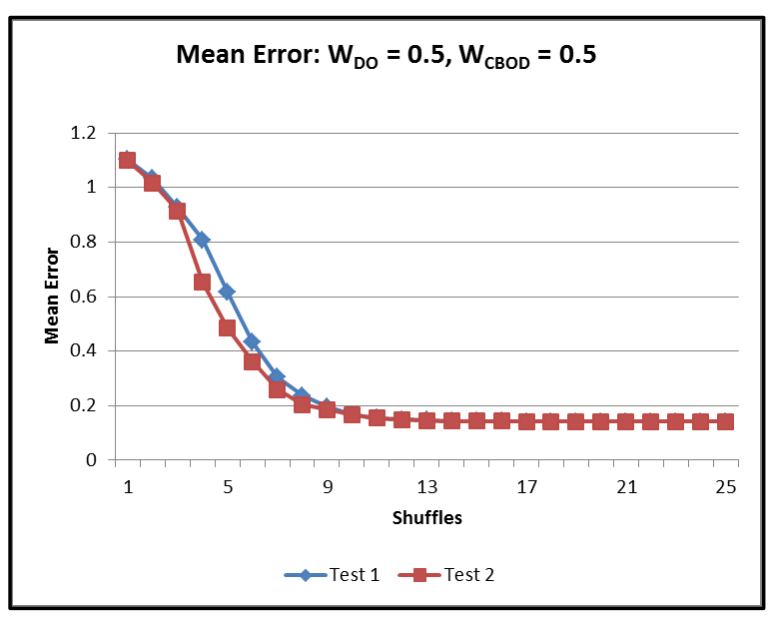

Figure 13: Experiment II - Mean Error.

This situation is probably due to the uncertainties in the experiment I related to field observations, non-computed sources from to diffuse pollution and the unviability of mapping and evaluating all the discharges, and the nature of the modeling process, which is by definition a simplification of the reality.

\section{Conclusions}

This study presented a new tool for automatic calibration of HEC-RAS NSM I water quality model. The calibration strategy uses the HEC-RAS controller to externally perform multiple model runs, where the parameters are determined by making use of the SCE-UA optimization algorithm, The developed tool, named as NSM-Controller, was tested in two experiments (a theoretical one and a real case study) in order to evaluate its performance. Regarding the theoretical experiment, the parameters determined by the NSM-Controller were close to the reference values considering several combinations of the calibrated parameters, but cases with higher dimensionality resulted in a lower performance and the need of a larger number of complexes and iterations for the SCE-UA optimization. When the NSM Controller was applied to a real case study, we found that aggregating multiple constituents (DO and BOD) into a weighted objective function provided more consistent results than a single objective function, while keeping the parameters within the expected ranges related to the characteristics of the assessed river.

As the developed tool is freely available, future user may want to include improvements, like the addition of more objective functions and the possibility of calibrate the dispersion coefficient. Future testing can also include the evaluation of the performance of the NSM-Controller in scenarios with more parameters being calibrated and complexes and iterations being employed. Furthermore, we believe that the NSM-Controller is an interesting option for calibrating the water quality module of a widely-known software like HEC-RAS. 
This manuscript is a non-peer reviewed preprint uploaded to EarthArXiv as an openaccess contribution.

\section{References}

Andrade, L.N., Mauri, G.R., Mendonça, A.S.F., 2013. General Multiobjective Model and Simulated Annealing Algorithm for Waste-Load Allocation. Journal of Water Resources Planning and Management 139, 339-344. https://doi.org/10.1061/(ASCE)WR.19435452.0000257.

Chiandussi, G., Codegone, M., Ferrero, S., Varesio, F.E., 2012. Comparison of multi-objective optimization methodologies for engineering applications. Computers and Mathematics with Applications 63, 912-942. https://doi.org/10.1016/j.camwa.2011.11.057.

Chin, D.A., 2006. Water-quality engineering in natural systems. Wiley-Interscience, Hoboken, N.J.

Churchill, M.A., Elmore, H.L., Buckingham, R.A., 1964. THE PREDICTION OF STREAM REAERATION RATES, in: Advances in Water Pollution Research. Elsevier, pp. 89-136. https://doi.org/10.1016/B978-1-4832-8391-3.50015-4.

Consórcio Gravataí, 2016a. Estudo de alternativas e projetos para minimização do efeito das cheias e estiagens na Bacia do Rio Gravataí - Produto no 10 - Relatório dos Estudos Hidrológicos.

Consórcio Gravataí, 2016b. Estudo de alternativas e projetos para minimização do efeito das cheias e estiagens na Bacia do Rio Gravataí - Relatório de andamento 12 - Produto № 07 Topobatimetria.

Demissie, Y., Yan, E., Wu, M., 2017. Hydrologic and water quality impacts of biofuel feedstock production in the Ohio River Basin. GCB Bioenergy 9, 1736-1750. https://doi.org/10.1111/gcbb.12466.

Dorigo, M., 1992. Optimization, learning and natural algorithms. (Ph.D. Thesis). Politecnico di Milano, Milan.

Duan, Q., Sorooshian, S., Gupta, V., 1992. Effective and efficient global optimization for conceptual rainfall-runoff models. Water Resources Research 28, 1015-1031. https://doi.org/10.1029/91WR02985.

Duan, Q., Sorooshian, S., Gupta, V.K., 1994. Optimal use of the SCE-UA global optimization method for calibrating watershed models. Journal of Hydrology 158, 265-284. https://doi.org/10.1016/0022-1694(94)90057-4.

Duan, Q.Y., Gupta, V.K., Sorooshian, S., 1993. Shuffled complex evolution approach for effective and efficient global minimization. Journal of Optimization Theory and Applications 76, 501-521. https://doi.org/10.1007/BF00939380. 
This manuscript is a non-peer reviewed preprint uploaded to EarthArXiv as an openaccess contribution.

Efstratiadis, A., Koutsoyiannis, D., 2010. One decade of multi-objective calibration approaches in hydrological modelling: a review. Hydrological Sciences Journal 55, 58-78. https://doi.org/10.1080/02626660903526292.

Gelda, R.K., Auer, M.T., Effler, S.W., Chapra, S.C., Storey, M.L., 1996. Determination of Reaeration Coefficients: Whole-Lake Approach. Journal of Environmental Engineering 122, 269-275. https://doi.org/10.1061/(ASCE)0733-9372(1996)122:4(269).

Goktas, R.K., Aksoy, A., 2005. The Impact of Objective Function Formulations on the Optimal Calibration of QUAL2E, in: Impacts of Global Climate Change. Presented at the World Water and Environmental Resources Congress 2005, American Society of Civil Engineers, Anchorage, Alaska, United States, pp. 1-6. https://doi.org/10.1061/40792(173)343.

Gupta, H.V., Sorooshian, S., Yapo, P.O., 1998. Toward improved calibration of hydrologic models: Multiple and noncommensurable measures of information. Water Resources Research 34, 751-763. https://doi.org/10.1029/97WR03495.

$\begin{array}{llll}\text { Hidroweb. } & \text { Héries } & \text { Históricas } & \text { Estações. }\end{array}$ http://www.snirh.gov.br/hidroweb/publico/medicoes_historicas_abas.jsf. (accessed 19 April 2019).

Holland, J.H. (1975). Adaptation in Natural and Artificial Systems. University of Michigan Press, Ann Arbor.

Karaboga, Dervis. (2005). An Idea Based on Honey Bee Swarm for Numerical Optimization, Technical Report - TR06. Technical Report, Erciyes University.

Kennedy, J., Eberhart, R., 1995. Particle swarm optimization, in: Proceedings of ICNN'95 International Conference on Neural Networks. Presented at the ICNN'95 - International Conference on Neural Networks, IEEE, Perth, WA, Australia, pp. 1942-1948. https://doi.org/10.1109/ICNN.1995.488968.

Leon, A.S., Goodell, C., 2016. Controlling HEC-RAS using MATLAB. Environmental Modelling and Software 84, 339-348. https://doi.org/10.1016/j.envsoft.2016.06.026.

Leonard, B.P., 1991. The ULTIMATE conservative difference scheme applied to unsteady onedimensional advection. Computer Methods in Applied Mechanics and Engineering 88, 17-74. https://doi.org/10.1016/0045-7825(91)90232-U.

Li, G., Cheng, C., Lin, J., Zeng, Y., 2007. Short-Term Load Forecasting Using Support Vector Machine with SCE-UA Algorithm. Third International Conference on Natural Computation (ICNC 2007). https://doi.org/10.1109/icnc.2007.660. 
This manuscript is a non-peer reviewed preprint uploaded to EarthArXiv as an openaccess contribution.

Lin, J.-Y., Cheng, C.-T., Lin, T., 2008. A Pareto Strength SCE-UA Algorithm for Reservoir Optimization Operation. 2008 Fourth International Conference on Natural Computation. https://doi.org/10.1109/icnc.2008.84.

Liu, Y., Gupta, H.V., Sorooshian, S., Bastidas, L.A., Shuttleworth, W.J., 2005. Constraining Land Surface and Atmospheric Parameters of a Locally Coupled Model Using Observational Data. Journal of Hydrometeorology 6, 156-172. https://doi.org/10.1175/JHM407.1.

Menezes, J.P.C. de, Bittencourt, R.P., Farias, M.D.S., Bello, I.P., Oliveira, L.F.C. de, Fia, R., 2015. Deoxygenation rate, reaeration and potential for self-purification of a small tropical urban stream. Revista Ambiente \&amp; Água 10, 748-757. https://doi.org/10.4136/ambi-agua.1599.

Nelder, J.A., Mead, R., 1965. A Simplex Method for Function Minimization. Comput J 7, 308313. https://doi.org/10.1093/comjnl/7.4.308.

Ning, S.K., Chang, N.-B., Yang, L., Chen, H.W., Hsu, H.Y., 2001. Assessing pollution prevention program by QUAL2E simulation analysis for the Kao-Ping River Basin, Taiwan. Journal of Environmental Management 61, 61-76. https://doi.org/10.1006/jema.2000.0397.

Nuruzzaman, M., Al-Mamun, A., Salleh, M.N.B., 2017. Experimenting biochemical oxygen demand decay rates of Malaysian river water in a laboratory flume. Environmental Engineering Research 23, 99-106. https://doi.org/10.4491/eer.2017.048.

Odu, G.O., Owaba, O.E.C., 2013. Review of Multi-criteria Optimization Methods - Theory and Applications. IOSR Journal of Engineering 3, 01-14. https://doi.org/10.9790/3021-031020114.

Pelletier, G.J., Chapra, S.C., Tao, H., 2006. QUAL2Kw - A framework for modeling water quality in streams and rivers using a genetic algorithm for calibration. Environmental Modelling and Software 21, 419-425. https://doi.org/10.1016/j.envsoft.2005.07.002.

Rong, N., Shan, B., Wang, C., 2016. Determination of Sediment Oxygen Demand in the Ziya River Watershed, China: Based on Laboratory Core Incubation and Microelectrode Measurements. International Journal of Environmental Research and Public Health 13, 232. https://doi.org/10.3390/ijerph13020232.

Santos, C.A.G., Suzuki, K., Watanabe, M., Srinivasan, V.S., 1999. OPTIMIZATION OF A RUNOFF-EROSION MODEL THROUGH A GENETIC ALGORITHM. PROCEEDINGS OF HYDRAULIC ENGINEERING 43, 557-561. https://doi.org/10.2208/prohe.43.557.

Siqueira, V.A., Sorribas, M.V., Bravo, J.M., Collischonn, W., Lisboa, A.M.V., Trinidad, G.G.V., 2016. Real-time updating of HEC-RAS model for streamflow forecasting using an optimization algorithm. RBRH 21, 855-870. https://doi.org/10.1590/2318-0331.011616086. 
This manuscript is a non-peer reviewed preprint uploaded to EarthArXiv as an openaccess contribution.

Storn, R., Price, K., 1997. Differential Evolution - A Simple and Efficient Heuristic for global Optimization over Continuous Spaces. Journal of Global Optimization 11, 341-359. https://doi.org/10.1023/A:1008202821328.

Sullivan, A.B., Snyder, D.M., Rounds, S.A., 2010. Controls on biochemical oxygen demand in the upper Klamath River, Oregon. Chemical Geology 269, 12-21. https://doi.org/10.1016/j.chemgeo.2009.08.007.

Tucci, C., Pilar, J., Bravo, J., Collischonn, W., 2008. Otimização de Regras de Operação de Reservatórios com Incorporação da Previsão de Vazão. Revista Brasileira de Recursos Hídricos 13, 181-196. https://doi.org/10.21168/rbrh.v13n1.p181-196.

Tucci, C., Bravo, J., Collischonn, W., 2009. Verificação da Eficiência e Eficácia de um Algoritmo Evolucionário Multi-objetivo na Calibração Automática do Modelo Hidrológico IPH II. Revista Brasileira de Recursos Hídricos 14, 37-50. https://doi.org/10.21168/rbrh.v14n3.p37-50.

van Griensven, A., Bauwens, W., 2003. Multiobjective autocalibration for semidistributed water quality models: Autocalibrations for Water Quality Models. Water Resources Research 39. https://doi.org/10.1029/2003WR002284

Vrugt, J.A., Gupta, H.V., Bastidas, L.A., Bouten, W., Sorooshian, S., 2003. Effective and efficient algorithm for multiobjective optimization of hydrologic models: MULTIOBJECTIVE OPTIMIZATION OF HYDROLOGIC MODELS. Water Resources Research 39. https://doi.org/10.1029/2002WR001746.

Wagener, T., van Werkhoven, K., Reed, P., Tang, Y., 2009. Multiobjective sensitivity analysis to understand the information content in streamflow observations for distributed watershed modeling: MULTIOBJECTIVE SENSITIVITY ANALYSIS. Water Resources Research 45. https://doi.org/10.1029/2008WR007347.

Wilcock, R.J., 1988. Study of River Reaeration at Different Flow Rates. Journal of Environmental Engineering 114, 91-105. https://doi.org/10.1061/(ASCE)07339372(1988)114:1(91).

Wu, J., Zhu, X., 2006. Using the Shuffled Complex Evolution Global Optimization Method to Solve Groundwater Management Models, in: Zhou, X., Li, J., Shen, H.T., Kitsuregawa, M., Zhang, Y. (Eds.), Frontiers of WWW Research and Development - APWeb 2006. Springer Berlin Heidelberg, Berlin, Heidelberg, pp. 986-995. https://doi.org/10.1007/11610113_105.

Xu, T., Liu, S., Liang, S., Qin, J., 2011. Improving Predictions of Water and Heat Fluxes by Assimilating MODIS Land Surface Temperature Products into the Common Land Model. Journal of Hydrometeorology 12, 227-244. https://doi.org/10.1175/2010JHM1300.1.

Yapo, P.O., Gupta, H.V., Sorooshian, S., 1998. Multi-objective global optimization for hydrologic models. Journal of Hydrology 204, 83-97. https://doi.org/10.1016/S0022-1694(97)00107-8. 
This manuscript is a non-peer reviewed preprint uploaded to EarthArXiv as an openaccess contribution.

Zhang, R., Qian, X., Li, H., Yuan, X., Ye, R., 2012. Selection of optimal river water quality improvement programs using QUAL2K: A case study of Taihu Lake Basin, China. Science of The Total Environment 431, 278-285. https://doi.org/10.1016/j.scitotenv.2012.05.063.

Zhang, Z., Wu, M., 2013. Evaluating the Transport and Fate of Nutrients in Large Scale River Basins Using an Integrated Modeling System, in: Fu, B., Jones, K.B. (Eds.), Landscape Ecology for Sustainable Environment and Culture. Springer Netherlands, Dordrecht, pp. 187-204. https://doi.org/10.1007/978-94-007-6530-6_10.

Zhang, R., Gao, H., Zhu, W., Hu, W., Ye, R., 2015. Calculation of permissible load capacity and establishment of total amount control in the Wujin River Catchment-a tributary of Taihu Lake, China. Environmental Science and Pollution Research 22, 11493-11503. https://doi.org/10.1007/s11356-015-4311-3. 